\title{
ISOLATION AND CHARACTERIZATION OF ANTIBIOTIC X-14547A, A NOVEL MONOCARBOXYLIC ACID IONOPHORE PRODUCED BY STREPTOMYCES ANTIBIOTICUS NRRL 8167
}

\author{
John W. Westley, Ralph H. Evans, Jr., Lilian H. Sello, Nelson Troupe, \\ ChaO-Min Liu and John F. Blount \\ Chemical Research Department, Hoffmann-La Roche Inc., \\ Nutley, New Jersey 07110, U.S.A.
}

(Received for publication October 24, 1978)

\begin{abstract}
A novel carboxylic acid ionophore, antibiotic X-14547A, closely related to the polyether antibiotics has been isolated along with four other metabolites from fermented cultures of a new strain of Streptomyces antibioticus. The structure, determined by X-ray analysis of the $\mathrm{R}(+$ )-1-amino-1-(4-bromophenyl)-ethane salt contained pyrrole carbonyl and trans-butadienyl chromophores in addition to the unusual tetrahydroindane bicyclic ring system. A second novel metabolite was identified as 3-ethyl-1,3-dihydro-3-methoxy-2H-indol-2-one.
\end{abstract}

Although the polyether antibiotics were first isolated in $1951^{1,2}$, the present high level of interest in these monocarboxylic acid ionophores began with the determination of the structure of monensin in $1967^{3)}$ and nigericin ${ }^{4)}$ the following year. These two antibiotics obviously constituted a new class of ionophores as they had many new structural features in common as well as similar ion transporting properties whether determined by equilibrium complexation in a single phase or distribution in two phases $^{5}$. One of the few differences between the two, was in their specific ionophore selectivity. Although both were shown to complex mono-, but not divalent, cations, monensin exhibits greatest affinity towards the $\mathrm{Na}^{+}$cation, whereas nigericin forms complexes better with $\mathrm{K}^{+}$. In contrast to these results, the third polyether to be structurally defined, lasalocid ${ }^{6,7}$, had both a different structure (aromatic chromophore, 3C-ethyls) and a strong affinity for divalent cations $\left(\mathrm{Ba}^{2+}, \mathrm{Ca}^{2+}\right)$ as well as the monovalent type $\left(\mathrm{Na}^{+}, \mathrm{K}^{+}\right)$.

Since 1970, while more than twenty of the monovalent polyethers have been characterized (e.g. dianemycin ${ }^{(5)}$, lenoremycin (Ro 21-6150) ${ }^{9}$, salinomycin ${ }^{10)}, \mathrm{A}_{204 \mathrm{~A}^{11)}}$ ) the structure of only three of the lasalocid-like divalent type have been solved, namely lysocellin ${ }^{12)}$, iso-lasalocid ${ }^{13)}$ and $\mathrm{A} 23187^{14}$. One of the latter, antibiotic A23187, contains a pyrrole-2-carbonyl moiety. The present report describes the characterization of a second novel pyrrole-ether (a recently proposed name for pyrrole containing monocarboxylic ionophores $\left.{ }^{15}\right)$, antibiotic X-14547A (1), which like lasalocid A forms complexes with both divalent and monovalent cations.

\section{Isolation and Characterization}

Antibiotic X-14547A (1), m.p. $138 \sim 141^{\circ} \mathrm{C},[\alpha]_{\mathrm{D}}-328^{\circ}\left(c 1, \mathrm{CHCl}_{3}\right)$, was isolated as part of a screen for novel ionophores, by ethyl acetate extraction of the whole fermentation broth from a novel culture of Streptomyces antibioticus NRRL 816716). The crude extract, worked up as shown in Scheme 1 yielded five different metabolites. The first one crystallized from the crude extract in good yield and was shown by nmr, uv and ms to be pyrrole-2-carboxylic acid, a metabolite produced via 4-hydroxy- 
L-proline by Spirillum serpens, Aerobacter aerogenes and Paracolobactrum aerogenoides ${ }^{17)}$. The second two products were isolated from an acetonitrile-hexane partition step and shown to be the iso-acids, 14-methylpentadecanoic and 15methylhexadecanoic acid reported previously as metabolites of Bacillus subtilis ${ }^{18}$.

Silica gel chromatography of the remaining extract yielded two novel microbial products, antibiotic X-14547A and a minor product identified as 3-ethyl-1,3-dihydro-3-methoxy-2H-indol2-one (2), m.p. $179^{\circ} \mathrm{C}$.

Characteristic of the ionophores, antibiotic $\mathrm{X}-14547 \mathrm{~A}$ is water-insoluble, but with alcohols, esters and diethyl ether, up to $10 \% \mathrm{w} / \mathrm{v}$ solubilities are possible and more concentrated solutions can be obtained with $\mathrm{CHCl}_{3}, \mathrm{CH}_{2} \mathrm{Cl}_{2}$, THF, DMF and DMSO. The antibiotic has $\mathrm{pKa}^{\prime}=$ 7.12 in $50 \%$ aqueous isopropanol and microanalysis, mass spectrometry (Fig. 1) and ${ }^{13} \mathrm{C} \mathrm{nmr}$ (Fig. 2) were all consistent with a molecular formula of $\mathrm{C}_{31} \mathrm{H}_{43} \mathrm{NO}_{4}$. In the ms, there was a molecular ion at $m / e 493$ and fragments ions at $m / e 475\left(\mathrm{M}-\mathrm{H}_{2} \mathrm{O}\right), 464\left(\mathrm{M}-\mathrm{C}_{2} \mathrm{H}_{5}\right), 446(\mathrm{M}$ $-\mathrm{C}_{2} \mathrm{H}_{5}-\mathrm{H}_{2} \mathrm{O}$ ), 251 (fragment 3) and a base peak at $m / e$ 94, strongly indicative of the pyrrole carbonyl cation, 4. In the ${ }^{13} \mathrm{C} \mathrm{nmr}$, thirty-one carbon signals were detected using $\mathrm{CH}_{2} \mathrm{Cl}_{2}$ as solvent. Single frequency off-resonance decoupling experiments resulted in the following assignments: $\delta 12.5,13.1,13.7,14.1\left(\mathrm{CH}_{3}\right) ; 21.5,22.0$, 26.5, 27.1, 27.5, $29.8\left(\mathrm{CH}_{2}\right) ; 30.4,40.6,41.2$, $44.0,45.0,50.1$ and $52.5(\mathrm{CH})$; 74.1, $75.4(\mathrm{CH}-$ O); $110.3,116.4,123.9,125.3,127.3,129.1,129.4$ and $132.3(\mathrm{CH}=\mathrm{C}) ; 132.4,140.8(\mathrm{C}=\mathrm{C}) ; 179.3$ and $191.6(\mathrm{C}=\mathrm{O})$ ppm (Fig. 2).

Further evidence for a pyrrole carbonyl chromophore was the maximum observed in the UV spectrum at $291 \mathrm{~nm}(\epsilon 16,100)$ in ethanol(Fig. 3). A second UV maximum at $244 \mathrm{~nm}(\epsilon 32,000)$ indicated the presence of a conjugated diene which was consistent with the ir spectrum in $\mathrm{KBr}$ disc (Fig. 4) showing an absorption peak at $1627(\mathrm{C}=\mathrm{C})$, in addition to carbonyl absorption at 1650 $(\mathrm{C}=\mathrm{CC}=\mathrm{O}), 1710$ and $1735 \mathrm{~cm}^{-1}\left(\mathrm{CO}_{2} \mathrm{H}\right)$. In the proton $\mathrm{nmr}$ spectrum of $\mathbf{1}$, (Fig. 5) resonances due
Scheme 1

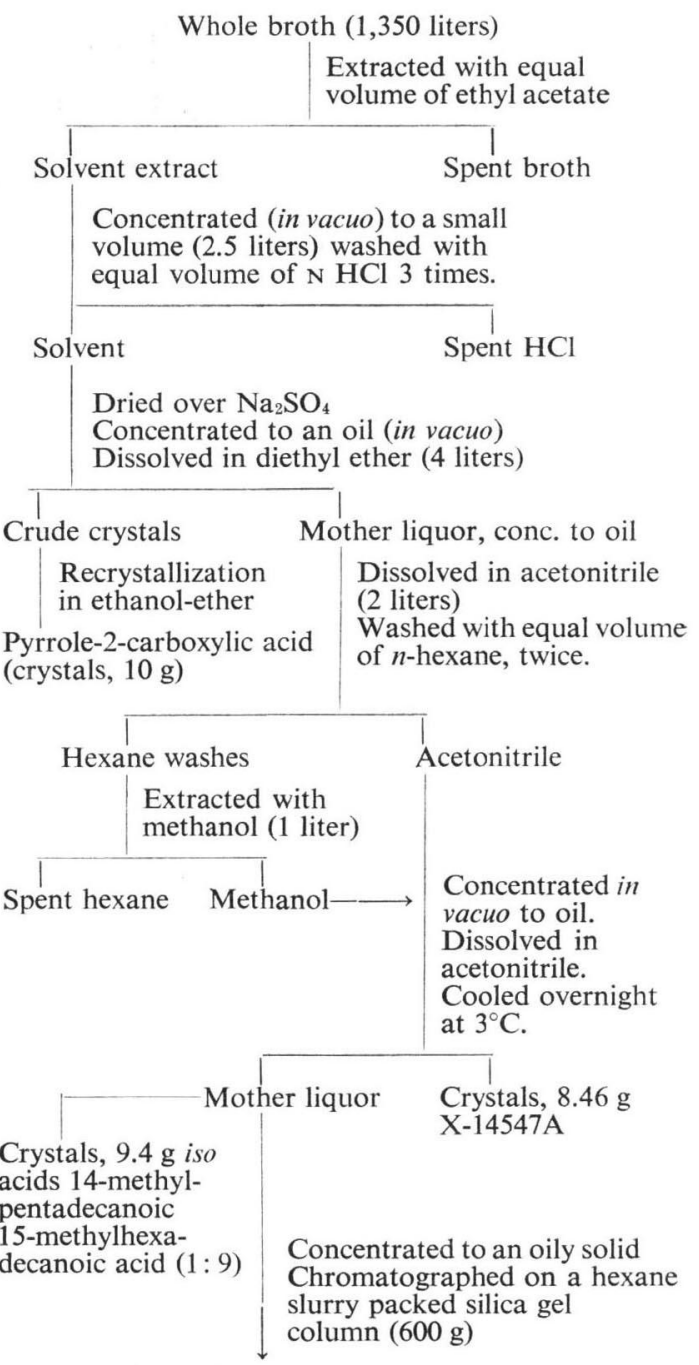

Eluted with $250 \mathrm{ml}$ hexane, then a gradient between 1 liter of $2 \%$ ethyl acetate in hexane to 1 liter of ethyl acetate - hexane $(3: 1)$, and then $500 \mathrm{ml}$ ethyl acetate.

Total yield of antibiotic $\mathrm{X}-14547 \mathrm{~A}=9.1 \mathrm{~g}$

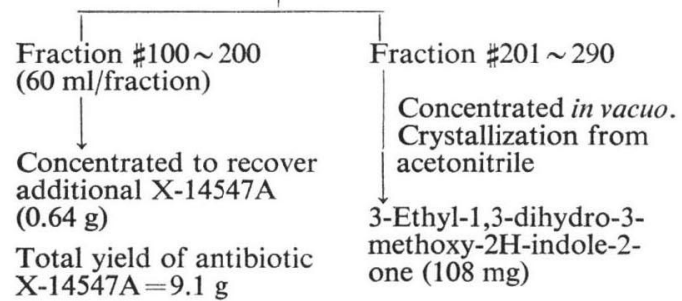




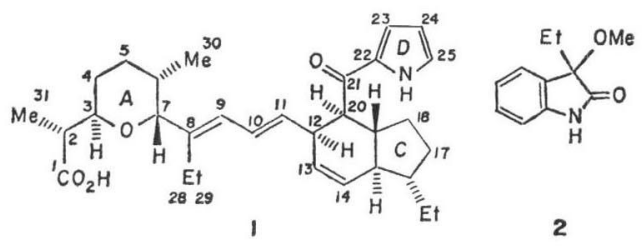

Fig. 1. Mass spectrum of X-14547A

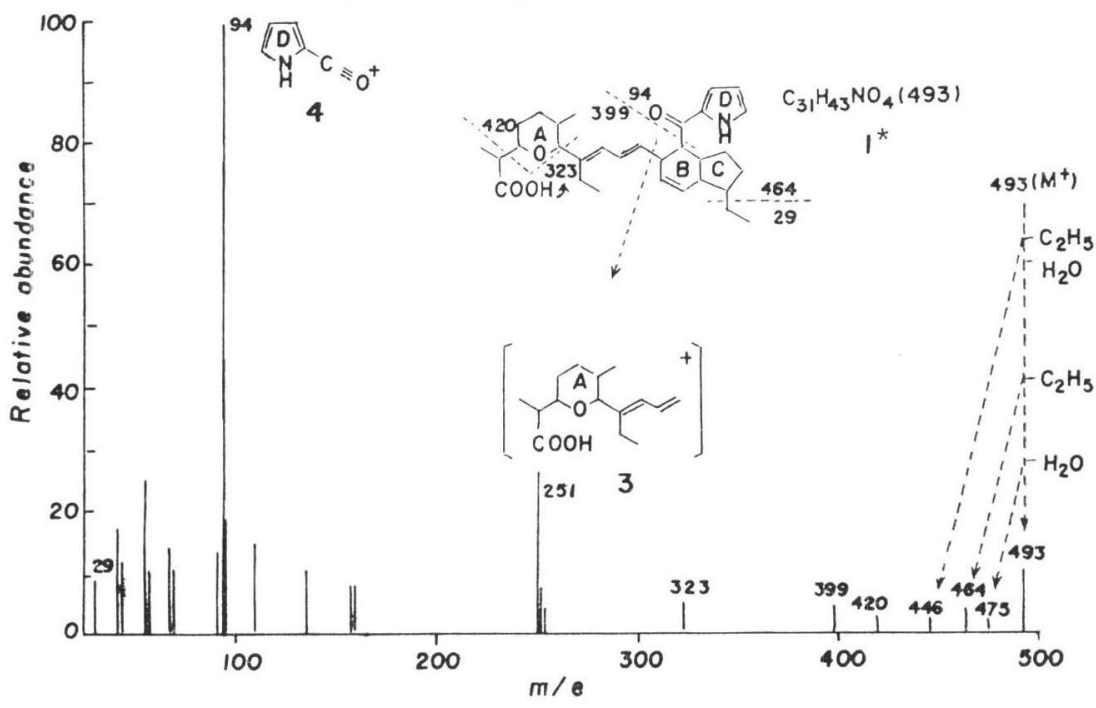

Fig. 2. ${ }^{13} \mathrm{C}$ nmr spectrum of $\mathrm{X}-14547 \mathrm{~A}$ in $\mathrm{CH}_{2} \mathrm{Cl}_{2}$

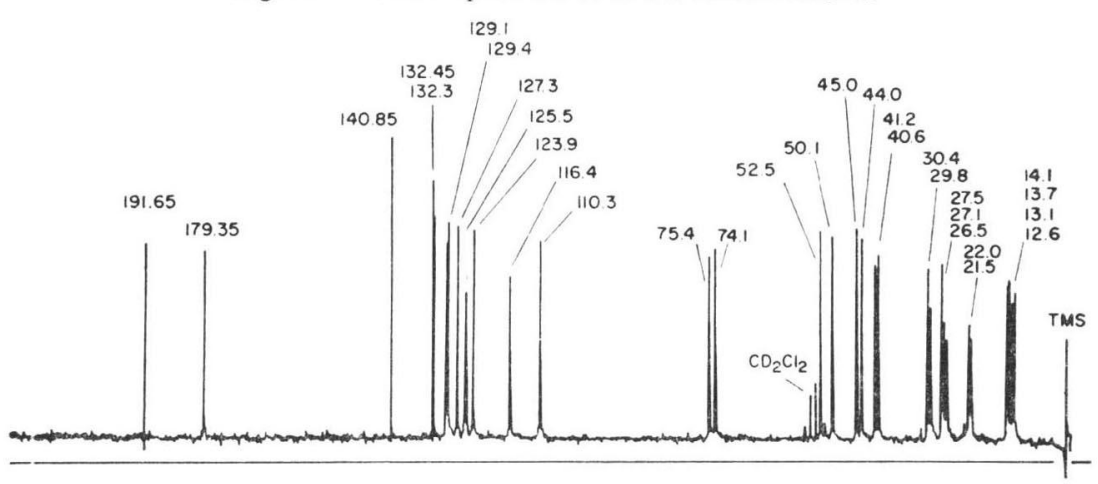

to four methyl groups were observed as triplets at $\delta 0.76,0.90\left(\mathrm{CH}_{3} \mathrm{CH}_{2}\right)$ and as doublets at $\delta 0.82$, $1.12\left(\mathrm{CH}_{3} \mathrm{CH}\right)$, four methines and six methylenes between $\delta 1.2$ and 2.2 in addition to five methines at $\delta 2.98\left(\mathrm{CH}-\mathrm{CO}_{2} \mathrm{H}\right), 3.35(\mathrm{CH}-\mathrm{CH}=\mathrm{CH}), 3.4(\mathrm{CH}-\mathrm{C}=\mathrm{O}), 3.9$ and $4.2(\mathrm{CH}-\mathrm{O}-\mathrm{CH})$, five vinylic protons between $\delta 5.1$ and $6.0(\mathrm{CH}=\mathrm{CH}, \underline{\mathrm{CH}}=\mathrm{CH}-\mathrm{CH}=\mathrm{C})$, one pyrrole proton at $\delta 6.22(\mathrm{CH}-\mathrm{CH}=\mathrm{CH}-\mathrm{NH})$ and two at $\delta 6.91(\mathrm{CH}-\mathrm{CH}=\mathrm{CH}-\mathrm{NH})$ and two exchangeable protons at $\delta 8.15\left(\mathrm{CO}_{2} \underline{\mathrm{H}}\right)$ and $10.25(\mathrm{NH})$.

The complete structure of antibiotic X-14547A was determined by X-ray analysis to be $\alpha(\mathrm{R})$, 5(S)-dimethy1-6(R)-[1-ethyl-4[4(R)-(2-pyrrolylcarbonyl)-1(S)-ethyl-3a(R),5(R),7a(R)tetrahydroindan5-yl]-1(E),3(E)-butadienyl]tetrahydropyran-2(R)acetic acid (1).

Unlike the polyethers solved earlier such as monensin ${ }^{3)}$ and lasalocid ${ }^{4)}$ where the heavy atom 
salts, $\mathrm{Ag}^{+}$and $\mathrm{Ba}^{2+}$ were analyzed by X-ray, or $\mathrm{A} 23187^{14}$ ) and $\mathrm{X}-206^{19}$ ), analyzed as free acids, the structure and absolute configuration of $\mathrm{X}$ $14547 \mathrm{~A}$ was determined from a crystal of the $R(+)$-1-amino-1-(4-bromophenyl)-ethane salt, m.p. $128 \sim 131^{\circ} \mathrm{C},[\alpha]_{\mathrm{D}}-303^{\circ}\left(c 1, \mathrm{CHCl}_{3}\right)$ (Fig. 6). The salt had been prepared as part of an investigation into the resolving power of lasalocid $^{20)}$ and related antibiotics towards asymmetric amines. Clearly, a cation containing an asymmetric carbon of known configuration makes the assignment of the asymmetric centers present in the antibiotic a considerably easier task than is normally the case. A unique aspect of the $R(+)-1-$ amino-1-(4-bromophenyl)-ethane salt of $\mathrm{X}-14547 \mathrm{~A}$ is the $2: 1$ stoichiometry found for antibiotic: amine in the salt complex although the antibiotic is a monocarboxylic acid and the amine is monobasic.

Crystals of the bromo-phenethylamine salt of $\mathbf{1}$ are tetragonal, space group $\mathrm{P}_{3} 22_{1} 2$, with $a=15.456(2), c=20.526(8) \AA$ and four $\left[\mathrm{C}_{31} \mathrm{H}_{43} \mathrm{NO}_{4}\right]_{2} \cdot \mathrm{C}_{8} \mathrm{H}_{10} \mathrm{NBr}$ dimers per unit cell. The dimers are located on the crystallographic two-fold axes. The two molecules of $\mathbf{1}$ comprising the dimer are related by the two-fold axis but the bromophenethylamine molecules are statistically disordered throughout the crystal. The crystal structure was solved by direct methods (Multan) and the final refinement was by block diagonal least squares in which the matrix was partitioned into five blocks. In the final refinement, anisotropic thermal parameters were used for the non-hydrogen atoms of the molecule of $\mathbf{1}$ and the bromine atom, and isotropic temperature factors were used for the other non-hydrogen atoms of the phenethylamine and all hydrogen atoms. The hydrogen atoms were included in the structure factor calculations but they were not refined. The final discrepancy indices were $R=0.107$ and $w R=0.128$
Fig. 3. UV spectrum of $\mathrm{X}-14547 \mathrm{~A}\left(\mathrm{C}_{2} \mathrm{H}_{5} \mathrm{OH}\right)$

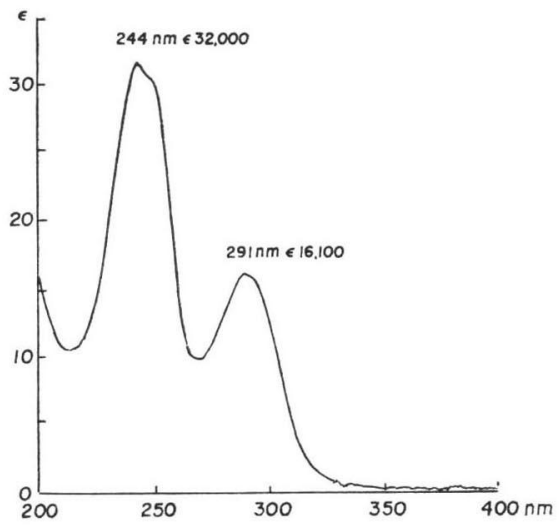

Fig. 4. IR spectrum of $\mathrm{X}-14547 \mathrm{~A}(\mathrm{KBr})$

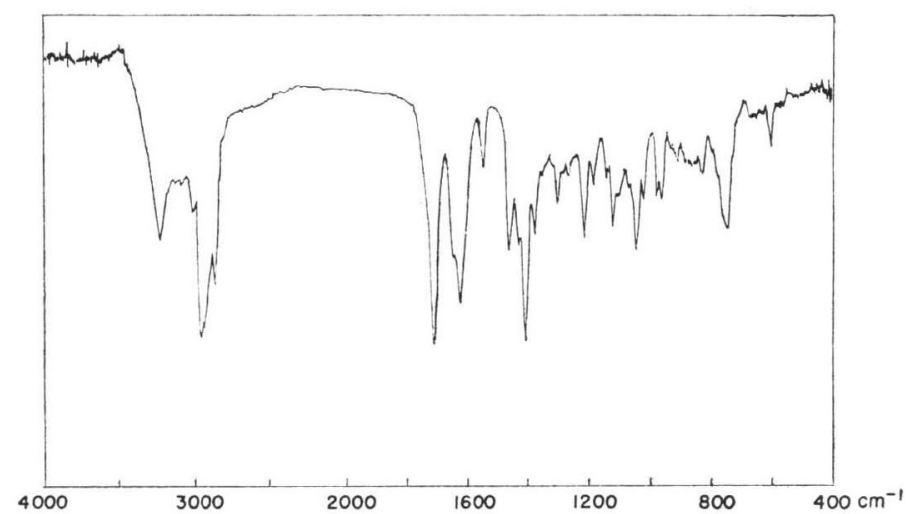

Fig. 5. NMR spectrum of $\mathrm{X}-14547 \mathrm{~A}\left(100 \mathrm{MHz}, \mathrm{CDCl}_{3}\right)$

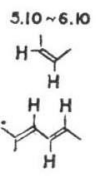

\section{d}

(

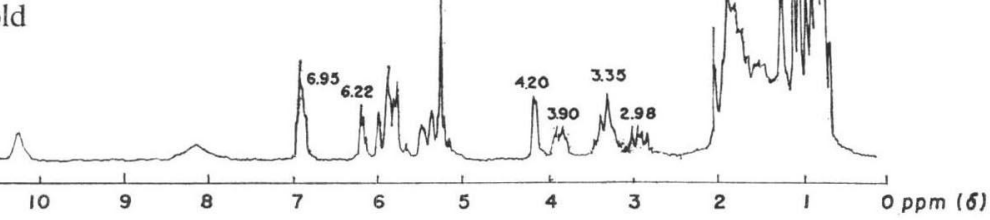


for 2154 observed reflections. The relatively high $\mathrm{R}$ values were due to mechanical problems with the diffractometer. The problem was not discovered until well after the experiment was completed and the structure had been fully refined.

In addition to the unusual stoichiometry of the amine salt, there are two structural elements in antibiotic X-14547A that have not been observed in any of the other polyether antibiotics. One novel feature is the $1(E), 3(E)$-butadiene system encompassing carbons C-8 to C-11 in 1, the first example of a diene in this class. The other unusual structural feature is the first example to be reported of a trans fused tetrahydroindane from natural sources, making the mechanism for the biosynthesis of the bicyclic system (rings B and C in Fig. 1) of considerable interest. Part of the molecule, 1, more characteristic of the polyethers is ring A which is identical to the analogous ring in salinomycin. Another part of the molecule found also in the first nitrogen-containing ionophore of the class, A23187, is the pyrrolyl chromophore referred to as ring D in Fig. 1.

From Fig. 6, the 'dimeric' nature of the salt complex can be characterized as two antibiotic molecules forming a jaw-like structure within which the ammonium salt is bound. The amine is held within the dimer by three hydrogen bonds, to O- 3 and the carbonyl O-4 of one antibiotic molecule (solid bonds in Fig. 6) and the carboxylate O-1 of the second, (open bonds in Fig. 6) molecule. The hydrogen bonds holding the two antibiotic molecules together are from $\mathrm{O}-1$ to $\mathrm{NH}^{\prime}, \mathrm{O}-1^{\prime}$ to $\mathrm{NH}$ and a third between the two other carboxyl oxygens, O-2 and O-2'. The 2:1 stoichiometry of the complex results from only one of the molecules of X-14547A (solid bonds in Fig. 6) being ionized in the complex, allowing the two O-2 oxygens to be hydrogen bound via the proton on the non-ionized carboxyl $\mathrm{OH}$ (in the open bonded molecule).

The indication from earlier experiments in the polyether class is that the formation of dimeric complexes in the crystalline state is accompanied by an ability to transport divalent as well as monovalent inorganic cations and this was confirmed for X-14547A in the conventional U-tube experiment by demoristrating the transport of radioactive ${ }^{45} \mathrm{Ca}^{2+}$ from one aqueous $\mathrm{CaCl}_{2}$ solution to another through a bulk organic phase $\left(\mathrm{CHCl}_{3}\right)$ on addition of the antibiotic. Subsequently, the calcium salt of X-14547A was formed and crystallized as a hemihydrate, $\left(\mathrm{C}_{31} \mathrm{H}_{42} \mathrm{NO}_{4}\right)_{2} \mathrm{Ca} \cdot \mathrm{H}_{2} \mathrm{O} ; \mathrm{m} . \mathrm{p} .179^{\circ} \mathrm{C},[\alpha]_{\mathrm{D}}$ $-401^{\circ}\left(c 1, \mathrm{CHCl}_{3}\right)$.

The taxonomy and microbiological characteristics of Streptomyces antibioticus NRRL 8167 and the antimicrobial and other biological activities of antibiotic X-14547A are presented in the accompanying paper $^{16)}$.

\section{Experimental}

A flow diagram outlining the isolation procedure for X-14547A is shown in Scheme 1 .

Physical Constants and Microanalyses

Pyrrole-2-carboxylic acid, m.p. $202 \sim 203^{\circ} \mathrm{C}$

Calcd. for $\mathrm{C}_{5} \mathrm{H}_{5} \mathrm{NO}_{2}$ (111.1) C 54.06, H 4.54, N 12.60

Found: $\quad$ C $54.33, \mathrm{H} 4.65, \mathrm{~N} 12.60$

Antibiotic X-14547A, m.p. $\left.138 \sim 141^{\circ} \mathrm{C} .[\alpha]_{\mathrm{D}}-328^{\circ}(c) 1, \mathrm{CHCl}_{3}\right)$.

Calcd. for $\mathrm{C}_{31} \mathrm{H}_{43} \mathrm{NO}_{4}(493.7)$ : C 75.42, H 8.78, N 2.84

Found:

C 75.57, H 8.92, N 2.67

3-Ethyl-1,3-dihydro-3-methoxy-2H-indole-2-one, m.p. $179^{\circ} \mathrm{C}$.

Caled. for $\mathrm{C}_{11} \mathrm{H}_{13} \mathrm{NO}_{2}(191.2)$ : C 69.09, H 6.85, N 7.33

Found:

C 69.02, H 6.96, N 7.19 
Fig. 6. Stereodrawings of the crystalline conformation of X-14547A, bromophenethylamine salt.
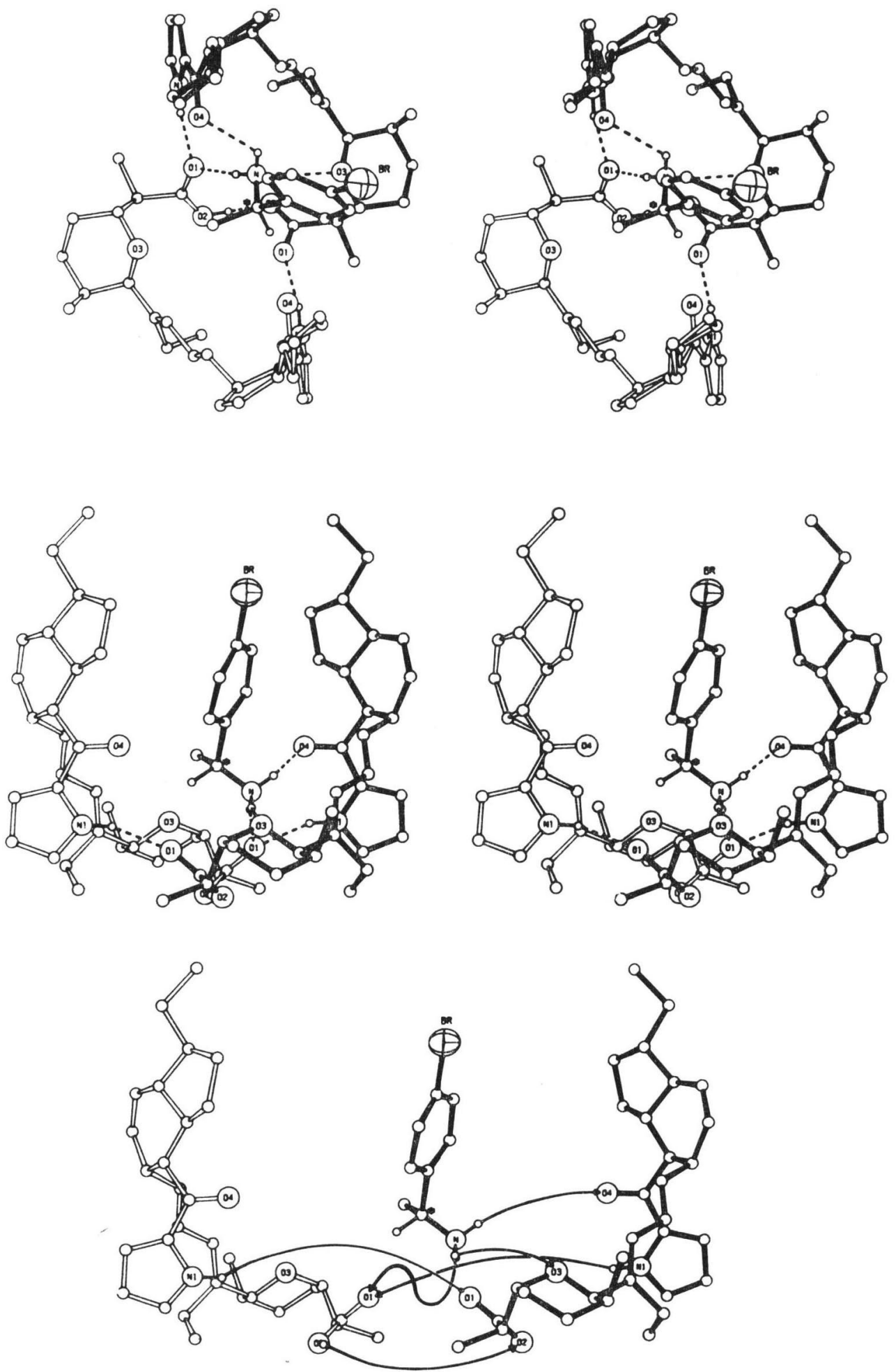
14-Methylpentadecanoic: 15 -methylhexadecanoic acids (9: 1), m.p. $52 \sim 54^{\circ} \mathrm{C},[\alpha]_{\mathrm{D}}-1.2^{\circ}\left(c 1, \mathrm{CH}_{3} \mathrm{OH}\right)$. Calcd. for $\mathrm{C}_{16} \mathrm{H}_{32} \mathrm{O}_{2}$ (256.4): $\quad$ C 74.94, $\mathrm{H} 12.58$ Found: $\quad$ C 74.93, H 12.97

Preparation of the $R(+)$-1-amino-1-(4-bromophenyl)-ethane salt of antibiotic X-14547A (1)

To a solution of $493 \mathrm{mg}$ ( 1 mmole) of 1 in methylene chloride was added a solution of $181 \mathrm{mg}$ of $R(+)$-1-araino-1-(4-bromophenyl)-ethane in methylene chloride. After stirring for 5 minutes, addition of $n$-hexane followed by slow evaporation gave a quantitative yield of the salt which on recrystallization had m.p. $128 \sim 131^{\circ} \mathrm{C},[\alpha]_{\mathrm{D}}-303^{\circ}\left(c 1, \mathrm{CHCl}_{3}\right)$ and was subsequently analyzed by X-ray crystallography. Microanalysis of the salt, which consisted of two molecules of $\mathbf{1}$ to one molecule of amine (Fig. 6):

Calcd. for $\mathrm{C}_{70} \mathrm{H}_{96} \mathrm{BrN}_{3} \mathrm{O}_{8}$ (1187.46): Found:

C 70.70, H 8.15, N 3.54, Br 6.73.

C 70.96, H 8.30, N 3.68, Br 6.83 .

\section{Preparation of the Calcium Salt of 1}

To a solution of $493 \mathrm{mg}$ of $\mathbf{1}$ in ethyl acetate was added an aqueous solution containing 3 mmole of $\mathrm{Ca}(\mathrm{OH})_{2}$. After shaking for 5 minutes, the two layers were allowed to separate and the solvent evaporated under reduced pressure to yield an amorphous salt which on recrystallization from acetoneacetonitrile yielded $490 \mathrm{mg}$ of the crystalline calcium salt of $1, \mathrm{~m} . \mathrm{p} .179^{\circ} \mathrm{C},[\alpha]_{\mathrm{D}}-401^{\circ}\left(\mathrm{c} 1, \mathrm{CHCl}_{3}\right)$.

$\begin{array}{cl}\text { Calcd. for }\left[\mathrm{C}_{31} \mathrm{H}_{42} \mathrm{NO}_{4}\right]_{2} \mathrm{Ca} \cdot \mathrm{H}_{2} \mathrm{O}(1043.5): & \mathrm{C} 71.37, \mathrm{H} 8.31, \mathrm{~N} \mathrm{2.68,} \mathrm{Ca} 3.84 \\ \text { Found: } & \text { C } 70.84, \mathrm{H} 8.32, \mathrm{~N} \mathrm{2.44,} \mathrm{Ca} 3.91\end{array}$

Acknowledgement

The authors wish to thank Dr. R. P. W. Scort and his staff of the Physical Chemistry Department, Hoffmann-La Roche for the spectral data.

\section{References}

1) Berger, J.; A. I. Rachlin, W. E. Scott, L. H. Sternaach \& M. W. Goldberg: The isolation of three new crystalline antibiotics from Streptomyces. J. Am. Chem. Soc. 73: 5295 5298, 1951

2) Harns:D, R. L.; P. H. Hidy, C. J. Corum \& K. L. Jones: A new crystalline antibiotic from an unidentified Streptomyces. Proc. Indiana Acad. Sci. 59: 38, 1950. Harned, R. L.; P. H. Hidy, C. J. Corum \& K. L. JoNEs: Nigericin, a new crystalline antibiotic from an unidentified Streptomyces. Antibiot. \& Chemoth. 1: 594 596, 1951

3) Agtarap, A.; J. W. Chamberlin, M. Pinkerton \& L. H. Steinrauf: The structure of monensic acid, a new biologically active compound. J. Am. Chem. Soc. 89: 5737 5739, 1967

4) Steink:auf, L. K.; M. Pinkerton \& J. W. Chamberlin: The structure of nigericin. Biochem. Biophys. Res. Commun. 33: 29 31, 1968

5) Pressman, B. C.: Biological applications of ionophores. Ann. Rev. Biochem. 45: 501 530, 1976

6) Johnson, S. M.; J. Herrin, S. J. Liu \& I. C. Paul: The crystal and molecular structure of an antibiotic containing a high proportion of oxygen. J. Am. Chem. Soc. 92: 4428 4434, 1970

7) Westiey, J. W.; R. H. Evans, Jr., T. Williams \& A. Stempel: Structure of antibiotic X-537A. Chem Commun. 1970: $71 \sim 72,1970$

8) Czerwinski, E. W. \& L. K. Steinrauf: Structure of the antibiotic, dianemycin. Biochem. Biophys. Res. Commun. 45: 1284 1287, 1971

9) Blount, J. F.; R. H. Evans, Jr., C.-M. Liu, T. Hermann \& J. W. Westley: X-Ray structure of Ro 21-6150, a polyether antibiotic related to dianemycin. Chem. Commun. 1975: 853-855, 1975; The name lenoremycin first appeared in ANTEunIS, M. J. O. \& G. VerheGGE: Solution conformation of the ionophore A204A Na+-salt. Bull. Soc. Chim. Belg. 86: 353 366, 1977

10) Kinashi, H.; N. ŌTAKe \& H. Yonehara: The structure of salinomycin, a new member of the polyether antibiotics. Tetrahed. Lett. 1973: 4955 4958, 1973

11) Jones, N. D.; M. O. Chaney, J. W. Chamberlin, R. L. Hamill \& S. Chen: Structure of A204A, a new polyether antibiotic. J. Am. Chem. Soc. 95: 3399 3400, 1973

12) Ôtakf, N.; M. Koenuma, H. Kinashi, S. Sato \& Y. Saito: The crystal and molecular structure of the silver salt of lysocellin, a new polyether antibiotic. Chem. Commun. 1975: 92 93, 1975

13) Westley, J. W.; J. F. Blount, R. H. Evans, Jr., A. Stempel \& J. Berger: Biosynthesis of lasalocid. II. 
X-Ray analysis of a naturally occurring isomer of lasalocid A. J. Antibiotics 27: 597 604, 1974

14) Chaney, M. O.; P. V. DeMarco, N. D. Jones \& J. L. Occolowitz: The structure of A23187, a divalent cation ionophore. J. Am. Chem. Soc. 96: 1932 1933, 1974

15) Westley, J. W.: Polyether antibiotics: Versatile carboxylic acid ionophores produced by Streptomyces. Adv. Appl. Microbiol. 22: 177 223, 1977

16) Liu, C.-M., T. E. Hermann, M. Liu, D. N. Bull, N. J. Palleroni, B. La-T. Prosser, J. W. Westley \& P. A. Miller: X-14547, a new antibiotic produced by Streptomyces antibioticus NRRL 8167. Discovery, fermentation, biological properties and taxonomy of the producing culture. J. Antibiotics 32: 95 99, 1979

17) Corpe, W. A.: Extracellular accumulation of pyrroles in bacterial culture. Appl. Microbiol. 11: 145 150,1963

18) Kaneda, T.: Fatty acids of the genus Bacillus: An example of branched chain preference. Bact. Rev. 41: $391 \sim 418,1977$

19) Blount, J. F. \& J. W. Westley: Crystal and molecular structure of the free acid form of antibiotic X-206. Chem. Commun. 1975: 533, 1975

20) Westley, J. W.; R. H. Evans, Jr. \& J. F. Blount: Optical resolution of asymmetric amines by preferential crystallization as lasalocid salts. J. Am. Chem. Soc. 99: 6057 6061, 1977 